\title{
Analysis on the Market Strategies of the Game Glory of Kings
}

\author{
Zongyu Huang
}

\author{
Saint Paul American School(Beijing), Beijing, 100192, China \\ *Corresponding author. Email: shilishuang@cas-harbour.org
}

\begin{abstract}
With the rapid development of electronic technology in China, the number of mobile phone users and the likeability of mobile games continue to increase. In the mobile game industry, in order to be among the best, the game producer will use some marketing strategy that helps them to attract more users to join. This article will study how some game promotes marketing and analyses some strategies they use. This paper will analyze the marketing strategy of the game Glory of Kings. Also, this paper will quote some papers about marketing strategy from "Ai Xue Shu" network, and some data from Baidu, Google and Bing. Moreover, this essay will summarize the three common marketing strategies, brand marketing, live broadcast and competitive marketing and cross-border marketing. As well as introducing how Glory of Kings uses these marketing strategies to become a leader in the mobile game industry. The research and collation of these marketing strategies will also provide better understanding and data collation for game players and some other game companies.
\end{abstract}

Keywords: Glory of Kings, marketing strategy, case study

\section{INTRODUCTION}

Glory of Kings is a mobile game that invented by Tencent company and officially tested on Android and IOS platforms on November 26, 2015. It is the world's first $5 \mathrm{v} 5$ hero fair fight mobile game. As a MOBA game, Glory of Kings is widely loved and praised by people and user and is one of the most popular game in the similar game. Glory of Kings has been nearly six years since it was opened, is always at the top of China's mobile game list during these 6 years. [1] According to the best-selling ranking of China's App Store mobile games provided by "Qi Mai" data, it has entered the top 10 of the day's sales on the day when the game first tested and become the top five after five days. Moreover, it entered the top three in January 2016, and finally reached the first place at the end of 2016. Since then, Glory of Kings has dominated the list almost all year round in 2017 and 2018. No matter how many new and interesting game come out, none of them can surpass him. In 2019, Tencent will launch another real-life gunfight type game, the $P U B G$ Mobile, which has exceeded the Glory of Kings for a few months. However, since 2020, the Glory of Kings has returned to the No.1 of the best-selling ranking, and has continued to this day. According to statistics, during the 2021 Chinese New
Year, the Glory of Kings released five costumes for its characters in the game, the sales volume reached 4.3 billion [2].

Successful sales are often inseparable from good sales strategies. The sales data of the Glory of Kings has a lot to do with its marketing model. Taking the game the Glory of Kings as an example, this article will explore the following questions by analyzing existing research and related data: Firstly, what marketing strategies are there? Secondly, what are the effects of different marketing strategies? Thirdly, what marketing strategies does King Glory adopted? By exploring the above issues, this article hopes to provide some references for the marketing of the game industry.

\section{LITERATURE REVIEW}

This article will mainly analyze the marketing strategy of the game Glory of Kings. Starting from the popularity of mobile games, this paper will provide some data and explanation to support that many young people are playing mobile games. Also, some data show the variety types and characteristics of mobile games. As well as listing some problems of the mobile game. Also, this paper will focus on three common marketing strategies. First, the brand marketing. The essay will 
provide the definition of brand marketing and the use in Eating Chicken, a kind of live shootout game. Second, live broadcasting and competition marketing. The paper is going to describe and explain this marketing through the rapid development of network platform and the benefits it can bring. Thirdly, cross-border marketing strategy. This strategy will be explained through definition and using the examples of Star Wars Commander and Star Wars: The Force Awakens. This article will focus on the embodiment and application of the game Glory of Kings in these three marketing strategies. In brand marketing, it attracts many customers and users through the influence of Tencent. Also, how Glory of Kings using Tik Tok, Huya and other platforms to attract the audience, and watch some KPL competition. As well as the cross-border marketing, the Glory of Kings uses three methods it. The product cross-border, content cross-border and channel cross-border, and using some examples to support it.

\subsection{The likeability of mobile game}

Mobile game is an emerging industry, which has been widely loved by players of all ages in recent years. According to statistics from [3], China has 650 million mobile game players in 2020 , with a total population of 1.42 billion people in the country, which account for about $45 \%$ of China's total population. Minus the elderly population of 255 million in 2020, there are about 55\% of China's young people are playing mobile games, and it is still rising every year. The variety of mobile game is also increasing as well. All kinds of game can make players experience different feelings. There is some action game, which can experience the real sense of attack and the pleasure of killing people. There are adventurous types, which can make players experience the sense of accomplishment. There are also many puzzle games, like international chess, Gobang and so on, with can help people to relax properly through some brain game.

Pricing of the game will basically follow the principle of free access, but when you buy the props and skin in the game, you need to pay a certain amount of money. This is because most of the young players will use their leisure time to play some game as a relax. Some office workers with financial conditions will choose to buy game props to quickly improve their strength and level in game. Of course, it does not rule out that some students use their pocket money to buy some game props to experience pleasure and release the pressure of learning. There is also some competitive game, such as eating chicken game, which were popular a few years ago, such as PUBG Mobile, Knives Out, and 5v5 confrontation game such as Glory of Kings. These games often provide some gorgeous skin and clothing effects to attract players and buy them. According to statistics [4], in 2020, the total revenue of the mobile game market have reached 209.676 billion yuan and is increasing by $32.61 \%$ from the previous year. The average consumption per user was 320.61 yuan and is increasing by 65.61 yuan from the previous year, which undoubtedly brought great benefits to the company.

However, there are many problems existed in mobile game. Although there are many kinds of mobile game, many of them are similar in style and content, which seriously lead to the innovation of the game and the ability to attract players. When a type of game is very popular, in a period of time, there will be many similar or basically consistent game with similar design and operation pop up. For example, there are many similar 5v5 competitive games like the Glory of Kings, such as Call of Time, Soul Blade Pocket Edition, Infinity Craft, The Endless Showdown, Vanity and etc. Such similar games will lead to low likeability to the unpopular ones, and it is difficult to have a unique style to be loved by people.

\subsection{Common marketing strategies}

The competition in the game market is very fierce. Every game wants to be loved and participated by a large number of players, so having some marketing methods is indispensable. Here are some common marketing strategies.

\subsubsection{Brand marketing}

Brand marketing strategy is to attract players through the influence of big brands behind the game. When several games of the same type and different brands are launched at the same time, players will be more likely to choose the brand they are most familiar with and the most famous one. For example, in the Eating Chicken types of game that opened a few years ago, NetEase and Tencent which are two big and famous game brands have both invented a mobile game about it, but Tencent's influence was higher than NetEase did. Therefore, before Tencent's creates the PUBG Mobile, the player often chooses NetEase's Eating Chicken game, the Knives Out rather than some other game companies. However, when Tencent produced the Eating Chicken game, the PUBG Mobile in 2017, a large number of NetEase's game players will choose Tencent's game, because they think that Tencent's influence will be greater, and the game will be better and more authentic.

\subsubsection{Live broadcast and competition marketing}

Live broadcast and competitive marketing attract players and unengaged users with some high-level operation, funny interpretation and some real-time competition recording. In modern days, more and more network platform has been developed, and live broadcast and competitive marketing have been one of 
the primary marketing strategies of most large-scale game. Now, many game players prefer to use some large platforms such as Tiger Tooth, Tik Tok to Live some game videos and to attract live players by funny speaking or professional operation. The addition of competition can also attract a lot of players. The game will create its own competition name, and through the spring, autumn, finals competition. It will also be broadcast live through various platforms, and the players can also enter the competition channel in the game to watch.

\subsubsection{Cross-border marketing}

Cross border marketing means that the two commodities complement each other in function, by linking two unrelated industries together to carry out and publicity together. Successful cross-border marketing can not only help the two brands improve their customers and image to the user, but also bring new experience to consumers [5]. For example, in January 2016, Star Wars Commander mobile game and Disney movie Star Wars: The Force Awakens were launched at the same time, they start a cross-border marketing, and reaching 200\% support through crowd funding, game gift packs and other activities.

\section{GLORY OF KINGS MARKETING STRATEGY}

\subsection{Brand marketing}

Glory of Kings is a game that produced by Tencent. Tencent has invented two famous chat software, WeChat and QQ, which are commonly used by people in modern days. Therefore, they attract many potential users who use WeChat and QQ to log in to the game. According to online data, [6] by the end of June 2021, the number of active accounts on WeChat has reached 963 million, while the number of active accounts on QQ has also reached 850 million. Secondly, Tencent's brand itself has great influence. It not only has WeChat and QQ, but also has many famous games. At the time when the Glory of Kings has just open, Tencent was also one of the top game brands, so it naturally attracted a lot of customers.

\subsection{Live broadcast and competition marketing}

Tencent has set up a total of five major competitions for King of Glory. There are TGA Grand Prix, QGC Professional League, King's Champions League, KPL Professional League, and International Invitational Tournament. The whole competition covers almost a year, and the content of the competition schedule is rich and wonderful, there are many powerful game clubs like Hero, TTG, DYG, eStar, AG, and etc. They all join the game and show their superb operation and unity of tacit cooperation. These events will be broadcasted to some live platforms and in game platforms to attract more game players [6]. According to 2020 figures, the Glory of Kings Grand Final has been watched by 570 million people, and in the first half of 2020, more than 3 million people registered for its various events and competition. These figures prove that the tournaments arranged by Tencent attract hundreds of millions of players, even some viewers who do not play the game. Also, millions of players have signed up for events and wants to participate in. These data can reflect the benefits brought by the Glory of Kings through live broadcasting strategy. Secondly, on many platforms, such as Tik Tok and Tiger Teeth, there are many anchors who play the Glory of Kings broadcast live to us every day, attracting more user in Tik Tok and Tiger Teeth through the interesting live broadcast and skilled operation

\subsection{Cross-border marketing}

Cross border marketing is a kind of marketing strategy that breaks the traditional marketing model. It is a kind of marketing strategy that two brands cooperate together to avoid fighting alone. In the cross-border marketing mode, there are three most commonly used modes: product cross-border, content cross-border and channel cross-border.

\subsubsection{Product cross-border}

The meaning of product cross-border is referring to a product will combine the characteristics of two brands together. This is because in this case, when the product is launched together with some well-known brands, the influence of other brands can be used to make the audience buy and be interested in another cooperative brand. For example, the cooperation of Glory of Kings and MAC. The two brands collaborated to produce a joint lipstick. Since there are more women than men attending the live events, Glory of Kings decided to partner with MAC Lipstick to attract more female players. In the collaboration, each of the heroes in the game will be paired with a lipstick color. The hero Mulan, for example, uses a red and blue color, so if a female player sees Mulan's lipstick that looks good, they might buy the lipstick. Similarly, when they like a lipstick color, they also want to buy Mulan, the hero. This would be a win-win situation for both the Glory of Kings and the Mac. Moreover, the game also has lot of cooperation with other brands like to launch new fashionable shoes with Adidas, launched jewelry with Zhou Sheng Sheng. These cross-border cooperation have made the reputation and popularity of the Glory of Kings continuously improve, and benefits of major cooperative brands are also growing.

\subsubsection{Content cross-border}

Content cross-border means that a brand can gain 
more users through a cross brand platform. The Glory of Kings once cooperated with New Era hat and launched a lot of King of Glory clothes and hats and invited some famous KPL professional players to show. This not only leverages the popularity of the clothing brand for marketing promotion, but also leverages what KPL players wear to attract more potential players of Glory of Kings. In this case, a customer who buys a suit or hat might want to join the game because of the logo on the suit, or someone who likes to play it might want to buy a suit or hat. The Glory of Kings also cooperated with G-SHOCK to attract more users by using its influence in China and abroad. The cooperation has no doubly help to increase public awareness of the game and to bring more reputation for it.

\subsubsection{Channel cross-border}

Channel cross-border refers to the use of cross-border partners' sales channels to implant their own products. For example, cooperation between Glory of Kings and Pai Ke pen. In this collaboration, Glory of Kings and Pai Ke launched a co-branded pen. Through adding some representing figures of the hero from the game on the pens, it can attract more customer to buy it. Pai Ke is one of the most sold pens in the country, and it will certainly attract a lot of customers. When they buy the pens whether because of demand or good looking, it will lead some buyers curious about the content of the game, so that they will download and join the game. This marketing through the Pai Ke sales channels has also brought great benefits to the game.

\section{RESULTS}

Due to the influence of various marketing strategies, the number of downloads and users of the Glory of Kings is continuing to increase. At the end of 2015, when the game just came out and in 2016, the game has been in the top ten of App store and has entered the top three for many times. However, it has not reached the position of No.1 download volume and No.1 in game ranking. However, after Tencent's efforts to promote the game Glory of Kings through various marketing means [6], as of 2021, Android alone has a total of $116,895,724,76$ downloads, and has been ranked first in IOS and Android game downloads and discussions for 2-3 years already. These data reflect the impact of marketing methods on the number of users and downloads of the Glory of Kings. Netizens are also full of praise for marketing use by the Glory of Kings. They all feel that the success of the game depends on spending a lot of money on marketing. Conversely, it's not easy and certainly right to put a lot of money into marketing like Glory of Kings. Players without a good vision of cooperation and own game strength will not match with teammates who meet expectations. Therefore, it is also very important to choose the appropriate marketing method.

\section{CONCLUSION}

China's game market is still expanding, and Glory of Kings is just one of many games. The reason why this game can stand out from tens of thousands of games and become the leader of mobile game is not only because of its rich content and exquisite design, but also because of its superb marketing strategy. Although the Glory of Kings not only uses brand, live broadcast, competition and cross-border marketing strategies, but it still can prove that these marketing methods have brought countless customers to the game. These marketing strategies are worth learning from other game, so as to make China's mobile game market more prosperous.

\section{AUTHORS' CONTRIBUTIONS}

This paper is independently completed by the author Zongyu Huang.

\section{ACKNOWLEDGMENTS}

First and foremost, I would like to show my deepest gratitude to my teachers and professors in my university, who have provided me with valuable guidance in every stage of the writing of this thesis.

Further, I would like to thank all my friends and roommates for their encouragement and support.

Without all their enlightening instruction and impressive kindness, I could not have completed my thesis.

\section{REFERENCES}

[1] Qimai Data. China App Store Top Sellers-iPhone-All Games. Accessed on June 28, 2021.

https://www.qimai.cn/rank/index/brand/grossing/de vice/iphone/country/cn/genre/6014

[2] Wangzhemieshixiong. The King of Glory Spring Festival costumes have been released, reaching 4.3 billion. How much have you contributed? https://baijiahao.baidu.com/s?id=16924892766669 $35869 \& \mathrm{wfr}=$ spider $\&$ for $=\mathrm{pc}$

[3] Chanyexinxi Net. The revenue development status of China and the global mobile game market in $2020 . \quad$ December $31,2020$. https://www.chyxx.com/industry/202012/920099.ht $\mathrm{ml}$

[4] Sohu.net. Seven classic cases of game cross-border marketing. February 8, 2016. https://www.sohu.com/a/58380933_117712 
[5] 360yangzhiwang. The number of WeChat users in 2021 will reach 963 million! Tencent's net profit in the second quarter of 2017 was 16.4 billion yuan. March 21, 2021.

http://www.360yangzhi.com/news/show-1735799.h tml
[6] Qseeking.net. See the three major models of brand cross-border marketing from the textbook-level marketing of the glory of the king. Accessed on June 28, 2021.

http://www.qseeking.com/news/805.html 